\title{
Adult myeloid leukaemia, geology, and domestic exposure to radon and $\gamma$ radiation: a case control study in central Italy
}

Francesco Forastiere, Alessandra Sperati, Giovanni Cherubini, Maria Miceli, Annibale Biggeri, Olav Axelson

\begin{abstract}
Objectives-To investigate whether indoor radon or $\gamma$ radiation might play a part in myeloid leukaemia as suggested by studies based on crude geographical or geological data for exposure assessment.

Methods-For six months radon and $\gamma$ radiation was measured with solid state nuclear track detectors and thermoluminescent dosimeters in dwellings of 44 adult male cases of acute myeloid leukaemia and 211 controls (all subjects deceased). Conditional logistic regression ORs (ORs) and $95 \%$ confidence intervals (95\% CIs) were estimated for quartiles of radon and $\gamma$ radiation and for municipality and dwelling characteristics.

Results-The risk of leukaemia was associated with an increasing urbanisation index ( $p$ value for trend=0.008). An increased OR was found among those living in more modern houses (OR 3.0, 95\% CI 1.4 to 6.6). Confirming the findings of a previous study in the same area, geological features bore a positive association with myeloid leukemia, even by adjusting for level of urbanisation. Contrary to expectations from the previous study, however, no association appeared between myeloid leukaemia and radon and $\gamma$ radiation; for the highest quartiles of exposure, ORs were $0.56(95 \% \mathrm{CI} 0.2$ to 1.4$)$ and 0.52 (95\% CI 0.2 to 1.4$)$, respectively. Considering only subjects who had lived $\geqslant 20$ years in the monitored home and adjusting for urbanisation, there was still no effect of exposure to radiation.

Conclusions-In view of the limited numbers, the results do not in general refute a possible risk of myeloid leukaemia from exposure to indoor radon or $\gamma$ radiation, but decrease the credibility of such a relation in the area studied and also of other studies suggesting an effect without monitoring indoor radiation. Some other fairly strong determinants have appeared-that is, level of urbanisation and living in modern houses-that might need further consideration.

(Occup Environ Med 1998;55:106-110)
\end{abstract}

Keywords: building material; epidemiology; radiation; urbanisation

A possible role of indoor exposure to ionising radiation for increasing the risk of myeloid leu- kaemia was suggested in the 1970s and early 1980s based on both correlation and analytical studies. ${ }^{1-3}$ More recently, geographically based investigations have suggested that indoor radon, a radioactive $\alpha$ emitting noble gas that emanates from the soil and from stony building materials, may have an aetiological role in this form of cancer. ${ }^{4-6}$ There is some biological plausibility for such an effect, as radon's decay products can accumulate in the fat cells of the bone marrow $^{7}$; moreover, aberrations in lymphocyte chromosomes ${ }^{8}$ and chromosomal instability in bone marrow cells ${ }^{9}$ have been found in populations exposed to radon. A relatively high proportion of cases of acute myeloid leukaemia have been postulated to be attributable to radon worldwide. ${ }^{5}$

The association between radon and myeloid leukaemia has been extensively debated, ${ }^{10}$ and no clearly increased risk of leukaemia has been found among miners exposed to radon. ${ }^{11}{ }^{12}$ As indoor radon concentrations may correlate with $\gamma$ radiation, when the main source of radon is the building material, a confounding role of exposure to $\gamma$ radiation has been suggested. ${ }^{13}$ To date there is no study of the link between myeloid leukaemia and measured indoor concentrations of radon.

Some years ago, we conducted an investigation in an area of central Italy that suggested an association between geological features of the ground and mortality from leukaemia which could possibly have reflected an effect of radon or background $\gamma$ radiation. ${ }^{14}$ We have now proceeded further by extending the observation period and by adding exposure data to that study. The results of this broader investigation are reported here. Because of the suggestive association found in the earlier study, that included men only, the present study is also restricted to men.

\section{Methods}

STUDY AREA

The volcanic nature of the soil within the province of Viterbo (285 000 inhabitants, 60 municipalities) entails a potential for greater radiation emission than nearby areas where the ground is mainly sedimentary. ${ }^{15}$ Radiation emission maps of the province have been drawn based on such geological features as type of rock, tectonic features, geothermic gradients, uranium deposits, and the presence of thermal waters. ${ }^{16}$ Tuff (tufo) from the volcanic area, which has a high emission of radon and thoron, ${ }^{17}$ has been widely used as the main 
building material in the province. Higher concentrations of indoor radon might therefore occur in constructions of tuff than in houses built from other materials (especially concrete).

\section{STUDY SUBJECTS}

The regional mortality register of Lazio was the source of both cases and controls for this study. A total of 44 cases of acute myeloid leukaemia (international classification of diseases (ICD) 205.0) were available for the period 1980-9 among men aged 35-80 who had lived in any of the municipalities of Viterbo province. A clinical confirmation of the diagnosis was obtained in all 35 cases who had died in hospitals.

Controls were selected from among the male deaths from other causes in the province during the same period. Five controls were enrolled for each case, matching for age at death ( \pm 2 years). The final sample of controls consisted of 211 subjects, as it was not possible to obtain a full set of controls for nine cases. The distribution of causes of death among the controls was the following: $40.8 \%$ cardiovascular diseases, $31.8 \%$ all other cancers (including 17 cases of lung cancer), 9.0\% respiratory diseases, $5.7 \%$ digestive disorders, $3.3 \%$ accidents, and $9.4 \%$ other causes.

\section{EXPOSURE ASSESSMENT}

The assessment of each subject's exposure was based on features of the municipality of residence, dwelling characteristics, and indoor radon and $\gamma$ radiation measurements. The home addresses were collected for both cases and controls from the registry offices. Each subject was classified according to the degree of urbanisation of his area of residence $(<2500$, 2500-4999, 5000-10 000, >10 000 inhabitants). Based on the geological features and the radiation emission maps described above, the province was divided in low, intermediate, and high radiation emission areas, ${ }^{16}$ and the subjects were classified accordingly. Measurements of radon and $\gamma$ radiation concentrations were made in the last dwelling where the cases and controls had lived, unless the subject had moved out during the past two years before death (18 subjects), or the last dwelling of residence was a nursing home (three subjects). For these subjects, measurements were done in the dwelling where the man had lived previously. For every home where measurements were made, the type of floor of the dwelling was noted along with the year of construction, the main building material, and whether the building had been structurally changed or renovated for insulation purposes.

Radon and $\gamma$ radiation were measured over six months, starting between November 1993 and March 1994, irrespective of the casecontrol status. In each dwelling two detectors for radon and two for $\gamma$ radiation were placed in the room that had been the subject's bedroom. Radon was measured by solid state nuclear track detectors (SSNDT, LR-115). Thermoluminescent dosimeters (TLD, GR200A) were used to measure $\gamma$ radiation. The measurements were done at the Environmental Physics
Laboratory of the Lazio region. The solid state nuclear track detectors were calibrated by the Italian National Agency for Environmental Protection at the National Radiation Protection Board (NRPB) in England. The calibration of $\gamma$ dosimeters was performed directly at the radiation facilities of the Nuclear Bacteriological Chemical (NBC) Military Centre of Civitavecchia (Italy). Results were expressed as the mean of the readings of the two detectors for radon and of the two detectors for $\gamma$ radiation, respectively. There was a good agreement between the two readings (for radon: mean difference $=2.6 \quad(\mathrm{SD} 29.5) \mathrm{Bq} / \mathrm{m}^{3}$, correlation coefficient $=0.98$; for $\gamma$ radiation: mean difference $=1.84(\mathrm{SD} 37.4) \mathrm{nGy} / \mathrm{h}$, correlation coefficient=0.97).

\section{STATISTICAL ANALYSIS}

The main factors influencing radiation levels were studied with analysis of variance (ANOVA) and multivariate linear regression analysis with the natural log of radon concentrations and $\gamma$ radiation, respectively, as the dependent variable. The regression results were expressed as the estimated differences in radiation by percentage - that is, by taking the exponential of the regression coefficients, subtracting one, and multiplying the result by $100-95 \%$ confidence intervals (95\% CIs) were also expressed as percentages. The relative risk for acute myeloid leukaemia relative to different exposures was assessed as ORs and 95\% CIs with conditional logistic regression. Odds ratios were estimated for surrogates of radiation exposure based on municipality and dwelling characteristics, as well as for quartiles of radon and $\gamma$ radiation. All the risk estimates were recalculated with adjustment for level of urbanisation.

\section{Results}

EXPOSURE ASSESSMENT

Table 1 shows the main characteristics of cases and controls. The mean age of the subjects was 68 (SD 10.5) years. Most of the cases (84.1\%) and controls $(82.0 \%)$ had been living in the same house for the past 10 years or more before death. For a few subjects, radiation measurements were not possible, and instead, the nearest, similar, dwelling within the same building was chosen. No measurements of radon could be made for one $(2.3 \%)$ case and 14 controls $(6.6 \%)$; for $\gamma$ radiation no measurement were obtainable for one case and 23 controls because of refusals or logistic difficulties.

Concentrations of radon and $\gamma$ radiation roughly followed a log normal distribution, with geometric means (GMs) of $147 \mathrm{~Bq} / \mathrm{m}^{3}$ (geometric standard deviation (GSD) 2.0) and $389 \mathrm{nGy} / \mathrm{h}$ (GSD 1.4), respectively. The corresponding arithmetic means were $186 \mathrm{~Bq} / \mathrm{m}^{3}$ and $415 \mathrm{nGy} / \mathrm{h}$. The interquartile ranges were 99-240 Bq/m $\mathrm{m}^{3}$ and $299-487 \mathrm{nGy} / \mathrm{h}$, respectively. Concentrations of radon and $\gamma$ radiation were moderately correlated $(r=0.56, p<0.001)$. On univariate analysis (table 2), the geological classification adopted was not associated with increases in either radon or $\gamma$ radiation, not even for the measurements taken in rooms in 
Table 1 Characteristics of leukaemia cases and controls enrolled in the study: Viterbo, Italy, 1980-9

\begin{tabular}{|c|c|c|c|c|}
\hline \multirow[b]{2}{*}{ Variable } & \multicolumn{2}{|c|}{ Cases $(n=44)$} & \multicolumn{2}{|c|}{ Controls $(n=211)$} \\
\hline & $n$ & $\%$ & $n$ & $\%$ \\
\hline \multicolumn{5}{|l|}{ Age $(y)$ : } \\
\hline $35-54$ & 7 & 15.9 & 29 & 13.7 \\
\hline $55-64$ & 6 & 13.6 & 30 & 14.2 \\
\hline $65-74$ & 18 & 40.9 & 86 & 40.8 \\
\hline $75-80$ & 13 & 29.5 & 66 & 31.3 \\
\hline \multicolumn{5}{|l|}{ Time of residence $(y)$ : } \\
\hline$<5$ & 2 & 4.5 & 12 & 5.7 \\
\hline $5-9$ & 5 & 11.4 & 22 & 10.4 \\
\hline $10-19$ & 14 & 31.8 & 62 & 29.4 \\
\hline$\geqslant 20$ & 23 & 52.3 & 111 & 52.6 \\
\hline Unknown & 0 & 0.0 & 4 & 1.9 \\
\hline \multicolumn{5}{|l|}{ Radon measurement: } \\
\hline Available same dwelling & 41 & 93.2 & 182 & 86.3 \\
\hline Available other dwelling $\star$ & 2 & 4.5 & 15 & 7.1 \\
\hline Not available & 1 & 2.3 & 14 & 6.6 \\
\hline \multicolumn{5}{|l|}{ Gamma measurement: } \\
\hline Available same dwelling & 41 & 93.2 & 174 & 82.5 \\
\hline Available other dwelling ${ }^{\star}$ & 2 & 4.5 & 14 & 6.6 \\
\hline Not available & 1 & 2.3 & 23 & 10.9 \\
\hline
\end{tabular}

${ }^{\star}$ Nearest, similar, dwelling within the same building.

Table 2 Geometric mean levels of radon and $\gamma$ radiation according to characteristics of the dwelling of residence: Viterbo, Italy, 1980-9

\begin{tabular}{|c|c|c|c|c|c|c|c|c|}
\hline \multirow[b]{2}{*}{ Variable } & \multicolumn{4}{|c|}{ Radon } & \multicolumn{4}{|c|}{$\gamma$ Radiation } \\
\hline & $n$ & $G M$ & $G S D$ & p Value & $n$ & $G M$ & $G S D$ & $p$ Value \\
\hline \multicolumn{9}{|l|}{ Geological features: } \\
\hline Low radiation & 77 & 153 & 1.93 & & 74 & 399 & 1.46 & \\
\hline Intermediate radiation & 62 & 179 & 1.83 & & 58 & 459 & 1.43 & \\
\hline High radiation & 101 & 124 & 2.01 & $<0.01$ & 99 & 344 & 1.34 & $<0.01$ \\
\hline \multicolumn{9}{|l|}{ Building material: } \\
\hline Tufft & 207 & 161 & 1.92 & & 200 & 412 & 1.38 & \\
\hline Concrete & 33 & 81 & 1.92 & $<0.01$ & 31 & 265 & 1.42 & $<0.01$ \\
\hline \multicolumn{9}{|l|}{ Date of construction: } \\
\hline$<1919$ & 113 & 164 & 2.34 & & 107 & 420 & 1.43 & \\
\hline $1919-45$ & 24 & 147 & 2.07 & & 24 & 354 & 1.36 & \\
\hline $1946-60$ & 45 & 140 & 2.05 & & 44 & 407 & 1.27 & \\
\hline$>1960$ & 57 & 118 & 2.54 & 0.04 & 55 & 327 & 1.48 & $<0.01$ \\
\hline Unknown & 1 & 308 & & & 1 & 602 & & \\
\hline \multicolumn{9}{|l|}{ Renovated building: } \\
\hline No & 119 & 125 & 1.93 & & 112 & 372 & 1.40 & \\
\hline Yes & 121 & 171 & 1.99 & $<0.01$ & 119 & 403 & 1.45 & 0.08 \\
\hline \multicolumn{9}{|l|}{ Floor of measurement: } \\
\hline Basement or ground & 50 & 200 & 1.88 & & 49 & 428 & 1.40 & \\
\hline Second floor & 114 & 143 & 2.01 & & 109 & 395 & 1.43 & \\
\hline Third floor & 57 & 120 & 1.93 & & 56 & 369 & 1.40 & \\
\hline$>$ Third floor & 19 & 130 & 1.90 & $<0.01$ & 17 & 311 & 1.39 & 0.01 \\
\hline \multicolumn{9}{|l|}{$\begin{array}{l}\text { Month measurement } \\
\text { began: }\end{array}$} \\
\hline November & 22 & 159 & 1.93 & & 39 & 420 & 1.40 & \\
\hline December & 31 & 150 & 1.95 & & 58 & 369 & 1.52 & \\
\hline January & 18 & 117 & 1.96 & & 52 & 361 & 1.39 & \\
\hline February & 34 & 158 & 2.17 & & 64 & 392 & 1.39 & \\
\hline March & 11 & 159 & 1.75 & 0.14 & 18 & 446 & 1.31 & 0.11 \\
\hline
\end{tabular}

$\mathrm{GM}=$ geometric mean; GSD=geometric SD. $\mathrm{p}$ Value from ANOVA. $†$ This category includes a few stone buildings.

the ground floor. Several dwelling factors, however, were associated with the levels of radiation. Houses built with tuff had the highest level of both radon and $\gamma$ radiation. Accordingly, older buildings, more often built with tuff, had higher concentrations of radon and $\gamma$ radiation. Renovated houses also had increased radon concentrations, presumably as a result of better insulation. Also, decreasing concentrations of both radon and $\gamma$ radiation were found at higher storeys. No effect of the period of the year was evident from the measurements.

In the multivariate analysis, building material (tuff $v$ concrete: $75 \%$ increase, $95 \%$ CI $38 \%$ to $123 \%)$, renovated house $(28 \%$ increase, $95 \%$ CI $8 \%$ to $50 \%$ ), and storey (second floor or more $v$ basement or ground floor: $27 \%$ decrease, $95 \%$ CI $11 \%$ to $40 \%$ ) were all independent predictors of radon concentrations, with the strongest effect being from tuff $v$ other building material. $\gamma$ Radiation levels were influenced only by the type of building material, tuff being associated with higher $\gamma$ radiation (54\% increase, $95 \%$ CI 36\% to $75 \%$ ).

ASSOCIATION BETWEEN EXPOSURE AND DISEASE

Table 3 shows the results of the univariate matched case-control analysis, including municipal and home characteristics. The risk of leukaemia was associated with an increasing urbanisation index ( $\mathrm{p}$ value for trend $=0.008$ ), with a significant OR of 3.1 for those living in towns with more than 10000 inhabitants. An association was found between leukaemia and the geological features of the soil, with a significantly raised OR of 2.5 for those living in areas classified in the highest category of radiation emission. The year of building construction bore a positive association with leukaemia ( $\mathrm{p}$ value for trend $=0.013$; OR 3.0 for more modern houses, built later than 1960). Finally, subjects living in concrete dwellings were at increased risk, OR 2.2. After adjustment for level of urbanisation, the increased risk was confirmed for areas with intermediate (OR 3.4; $95 \%$ CI 1.1 to 11 ) and high radiation emission (OR 2.1; 95\% CI 0.9 to 5.1 ), and for more modern buildings (OR 2.9; 95\% CI 1.3 to 6.5 ); the OR for concrete dwellings was reduced to 2.0 (95\% CI 0.89 to 4.6 ).

Table 4 shows the risks of leukaemia relative to quartiles of the measured concentrations of radon and $\gamma$ radiation. No association was found, although there was a paradoxical hint of a negative relation (the ORs were $0.51,0.66$, and 0.56 for quartiles of radon, and $0.89,0.58$, and 0.52 for quartiles of $\gamma$ radiation, respectively). When adjustment was made for level of urbanisation, the ORs were practically the same $(0.55,0.65$, and 0.61 for radon, and 1.0, 0.69 , and 0.63 for $\gamma$ radiation, respectively). Again the same result was found when analysis was restricted to the 23 cases who had lived 20 years or more in the monitored home, with their respective controls (table 4), or when the exposure distribution among the controls was taken to define quartiles. The results were not sensitive to the presence of cancer subjects in the control series as practically the same ORs were obtained when cancer cases (or only lung cancer cases) were excluded from the controls (data not shown). Furthermore, the risk of leukaemia was still not associated with increasing radon concentration when the same categories for radon exposure were chosen that had been used in another larger study of indoor radon and lung cancer. ${ }^{18}$ Taking a radon concentration lower than $80 \mathrm{~Bq} / \mathrm{m}^{3}$ as the reference, the ORs were $0.51,0.52$, and 0.63 for those living in houses with 80-140, 141-400, and >400 $\mathrm{Bq} / \mathrm{m}^{3}$, respectively (none of these decreased ORs were significantly different from unity).

\section{Discussion}

This investigation involves few subjects, but it is to our knowledge the first study dealing with the relation between measured concentrations of indoor radon and leukaemia. Considering 
Table 3 Association between myeloid leukaemia and characteristics of the place and dwelling: Viterbo, Italy 1980-9

\begin{tabular}{|c|c|c|c|c|}
\hline Variable & $\begin{array}{l}\text { Cases } \\
(n=44)\end{array}$ & $\begin{array}{l}\text { Controls } \\
(n=211)\end{array}$ & OR & $95 \% C I$ \\
\hline \multicolumn{5}{|l|}{ Area of residence: } \\
\hline \multicolumn{5}{|c|}{ Degree of urbanisation (inhabitants): } \\
\hline$<2500$ & 4 & 46 & 1.0 & \\
\hline $2500-4999$ & 6 & 50 & 1.2 & 0.3 to 4.7 \\
\hline $5000-10000$ & 11 & 39 & 3.0 & 0.8 to 9.9 \\
\hline$>10000$ & 23 & 76 & 3.1 & 1.0 to 9.1 \\
\hline \multicolumn{5}{|l|}{ Geological features: } \\
\hline Low radiation & 8 & 75 & 1.0 & \\
\hline Intermediate radiation & 13 & 52 & 2.4 & 0.9 to 6.3 \\
\hline High radiation & 23 & 84 & 2.5 & 1.0 to 5.8 \\
\hline \multicolumn{5}{|l|}{ Dwelling: } \\
\hline \multicolumn{5}{|c|}{ Date of building construction: } \\
\hline$<1919$ & 14 & 107 & 1.0 & \\
\hline $1919-45$ & 3 & 21 & 1.2 & 0.3 to 4.8 \\
\hline $1946-60$ & 10 & 37 & 2.2 & 0.9 to 5.6 \\
\hline$>1960$ & 17 & 45 & 3.0 & 1.4 to 6.6 \\
\hline Unknown & 0 & 1 & - & - \\
\hline \multicolumn{5}{|c|}{ Concrete as building material: } \\
\hline No & 34 & 188 & 1.0 & \\
\hline Yes & 10 & 23 & 2.2 & 1.0 to 4.9 \\
\hline \multicolumn{5}{|l|}{ Renovated dwelling: } \\
\hline No & 25 & 100 & 1.0 & \\
\hline Yes & 19 & 111 & 0.7 & 0.3 to 1.7 \\
\hline \multicolumn{5}{|l|}{ Floor: } \\
\hline Basement or ground & 8 & 45 & 1.0 & \\
\hline Second floor & 14 & 77 & 1.0 & 0.4 to 3.3 \\
\hline Third floor & 6 & 37 & 0.9 & 0.2 to 3.0 \\
\hline$>$ Third floor & 16 & 52 & 1.7 & 0.7 to 6.4 \\
\hline
\end{tabular}

the positive link that we originally found between certain geological features and acute myeloid leukaemia in the Viterbo area, ${ }^{14}$ and recognising that tuff is widely used as a building material, there was certainly a strong suspicion that background radiation could play a part. Moreover, an Italian case-control study suggested an increased risk of myeloid leukaemia among subjects who had lived in dwellings made with tuff. ${ }^{19}$ Although confirming our earlier study as reporting an association between acute myeloid leukaemia and geological characteristics that determine radiation from the ground, the addition of specific exposure data has not shown any role for indoor exposure to radon and $\gamma$ radiation.

The $95 \%$ CIs for the risk estimates do not exclude the possibility of a positive relation in general, but the results refute our original hypothesis that exposure to indoor radon or $\gamma$ radiation could be responsible for the association of myeloid leukaemia with geological characteristics in the study area. The findings also tend to detract credibility from the previously found geographical correlation between mean radon concentrations and myeloid leukaemia ${ }^{56}$ and the hypothesis that exposure to domestic radon is one of the main aetiological factors for acute myeloid leukaemia. ${ }^{5}$ Instead other fairly robust determinants of risk for leukaemia appeared, although currently not interpretable in any biologically meaningful sense.

Somewhat surprisingly, we found no positive association between indoor radon and $\gamma$ radiation and geological features indicating higher radiation emission from the soil. Instead building material turned out to play the overwhelming part in determining indoor radiation in this area. Levels of radon and $\gamma$ radiation were correlated with and both depend mainly on the building material. Tuff seems to be an important factor for increased exposure to background radiation and is responsible for the higher indoor radon concentrations found in the study area than in the whole of Italy - that is, $185 \mathrm{~Bq} / \mathrm{m}^{3} v 77 \mathrm{~Bq} / \mathrm{m}^{3} .^{20}$ For indoor radon, a relatively small contribution from the soil was indicated by the lower concentrations found for apartments above the ground floor; in the multivariate analysis, the storey had no effect on $\gamma$ radiation, which was only affected by building material.

The results of the case-control analysis on the positive and negative associations with geological classification and the indoor radiation levels, respectively, are puzzling. It may be speculated that the volcanic background being an apparant determinant of acute myeloid leukaemia in the data depends on the role of some elements, perhaps even radon occurring in drinking water. ${ }^{2122}$ This issue should be studied in more detail.

Studying the possible effects of low widespread exposures is problematic, especially because there is no truly unexposed reference category available and large numbers are required to obtain sufficient power. Exposure assessment is another critical issue when there are only small differences between those in the

Table 4 Association between leukaemia and concentration of radon and $\gamma$ radiation in the dwelling: Viterbo, Italy, 1980-9

\begin{tabular}{|c|c|c|c|c|c|}
\hline & Range of values & Cases & Controls & $O R$ & $95 \% C I$ \\
\hline \multicolumn{6}{|c|}{ Entire sample: } \\
\hline \multicolumn{6}{|c|}{ Radon (quartiles) $(\mathrm{Bq} / \mathrm{mc})$ : } \\
\hline 1 & $(22-99)$ & 15 & 45 & 1.00 & \\
\hline 2 & $(100-145)$ & 8 & 51 & 0.51 & 0.2 to 1.3 \\
\hline 3 & $(146-230)$ & 11 & 50 & 0.66 & 0.3 to 1.6 \\
\hline 4 & $(231-1200)$ & 9 & 51 & 0.56 & 0.2 to 1.4 \\
\hline \multicolumn{6}{|c|}{ Gamma radiation (quartiles) $(\mathrm{nGy} / \mathrm{h})$ : } \\
\hline 1 & $(118-299)$ & 13 & 42 & 1.00 & \\
\hline 2 & $(300-391)$ & 14 & 44 & 0.89 & 0.4 to 2.2 \\
\hline 3 & $(392-487)$ & 8 & 53 & 0.58 & 0.2 to 1.5 \\
\hline 4 & $(488-934)$ & 8 & 49 & 0.52 & 0.2 to 1.4 \\
\hline \multirow{2}{*}{\multicolumn{6}{|c|}{$\begin{array}{l}\text { Analysis restricted to cases and controls living } \geqslant 20 \mathrm{y} \text { in the same dwelling: } \\
\text { Radon (quartiles) }(\mathrm{Bq} / \mathrm{mc}) \text { : }\end{array}$}} \\
\hline & & & & & \\
\hline 1 & $(27-99)$ & 8 & 12 & 1.00 & \\
\hline 2 & $(100-157)$ & 7 & 14 & 0.87 & 0.2 to 2.9 \\
\hline 3 & $(158-257)$ & 4 & 18 & 0.30 & 0.0 to 1.4 \\
\hline 4 & $(258-608)$ & 4 & 16 & 0.48 & 0.1 to 1.8 \\
\hline \multicolumn{6}{|c|}{ Gamma radiation (quartiles) (nGy/h): } \\
\hline 1 & $(200-304)$ & 7 & 12 & 1.00 & \\
\hline 2 & $(305-379)$ & 7 & 14 & 0.70 & 0.1 to 2.6 \\
\hline 3 & $(380-482)$ & 5 & 15 & 0.41 & 0.0 to 1.9 \\
\hline 4 & $(483-780)$ & 4 & 16 & 0.29 & 0.0 to 1.5 \\
\hline
\end{tabular}


highest and lowest exposure category. For indoor exposures an additional problem is that the subjects only spend limited time in their homes, thus obtaining exposure elsewhere as well; such exposure is usually impossible to assess. This study certainly has considerable limitations in all these respects as far as exposure to indoor radon and $\gamma$ radiation is concerned. Nevertheless, the tendency to a slight inverse relation with acute myeloid leukaemia is remarkable and despite the small population size, the original hypothesis of an increased risk is is almost refuted. The result is the more remarkable as an increased risk was found in the previous study, where living in a volcanic and radon emanating area was taken as the exposure.

An association between leukaemia and level of urbanisation has been already described, and higher rates have been found in urban areas where income and physician density are higher. ${ }^{23}$ A geographical clustering of childhood leukaemia has been found in Great Britain $^{24}$ and in the United States ${ }^{25}$ and population density seemed to be a main determinant suggested to be a surrogate for some viral factor. The influence of urbanisation in our study might reflect a variety of low level exposures, some of them occupational. Especially, exposure to benzene in gasoline and car exhausts as well as to other pollutants could be of importance. ${ }^{26}$ The association of leukaemia with modern houses is even less clear and difficult to interpret but could perhaps be looked upon as a proxy for several factors, including indoor chemical exposures from paints, wall papers, plastic materials in carpets, and possibly newer types of furniture.

The low statistical power of the study has already been mentioned. Given $\alpha=0.05$ and power $=0.8$, the study would have been able to detect a linear trend over the exposure quartiles only with $\mathrm{ORs} \geqslant 1.5, \geqslant 2.5$, and $\geqslant 3.7$. As a further limitation, cases were dead men and not subjects with newly diagnosed disease; moreover, although the clinical diagnosis of most cases was confirmed from hospital records, the possibility of some misclassification of the disease and a dilution of the effect still remains. Finally, the choice of cancer controls may be criticised as in some of these subjects the disease could be due to the exposure under study. However, this possibility is minimal when all cancer sites (within a larger group of subjects with other diseases) are considered as controls. The results of the study were insensitive to the presence of cancer subjects among controls.

Assessment of exposure to radiation in this study covered only the last dwelling of residence and not most of the subject's life history, as in studies of radon exposure and lung cancer, ${ }^{18}$ so the possibility for exposure misclassification should be underlined. As a result of the limited amount of data, we could not explore the possible effect of cumulative exposure (or of time weighted average exposure). However, we did not find an effect when the analysis was restricted to those subjects living for a long period in the same dwelling; furthermore, the relevant induction latency period for myeloid leukaemia tends to be shorter than that for lung cancer.

In conclusion, our primary hypothesis that exposure to ionising radiation in the home environment is a possible determinant of acute myeloid leukaemia is not supported by the present exposure measurements and analyses. Although our originally identified geographical factor still remains, it seems to represent something other than exposure to indoor radiation. Urbanisation and modern houses also emerged as other biologically unclear determinants of this disease.

We thank Dr Brunella Terenzoni, Mr Alessandro Citeroni, $\mathrm{Mr}$ Marco Menegaldo, and Dr Augusto Quercia for their valuable help in collecting the data, Dr Francesco Bochicchio for his thoughtful comments, and Mrs Anna Emigli for typing. We also acknowledge Dr Susan Levenstein for her critical review of the manuscript.

1 Jacobsen A, Plato AP, Frigerio NA. The role of natural radiations in human leukemogenesis. Am $\mathcal{F}$ Public Health $1976 ; 66: 31-7$.

2 Flodin U, Andersson L, Anjou CG, et al. A case-referent study on acute myeloid leukemia, background radiation and exposure to solvents and other agents. Scand $\mathcal{F}$ Work Environ Health 1981;7:924-32.

3 Edling C, Comba P, Axelson O, et al. Effects of low-dose radiation: a correlation study. Scand $\mathcal{f}$ Work Environ Health 1982;8:59-64

4 Lucie NP. Radon exposure and leukaemia. Lancet 1989;ii: 99-100.

5 Henshaw DL, Eatough JP, Richardson RB. Radon as a causative factor in the induction of myeloid leukaemia and other cancers. Lancet 1990;335:1008-12.

6 Viel JF. Radon exposure and leukaemia in adulthood. Int 7 Epidemiol 1993;22:627-31.

7 Richardson RB, Eatough JP, Henshaw DL. Dose to red Richardson $\mathrm{RB}$, Eatough $\mathrm{JP}$, Henshaw $\mathrm{DL}$. Dose to red
bone marrow from natural radon and thoron exposure. $\mathrm{Br}$ bone marrow from natural

F Radiol 1991;64:608-24.
8 Bridges BA, Cole J, Arlett CF, et al. Possible association between mutant frequency in peripheral lymphocytes and domestic radon concentrations. Lancet 1991;337:1187-9.

9 Kadhim MA, Lorimore SA, Hepburn MD, et al. Particleinduced chromosomal instability in human bone marrow cells. Lancet 1994;344:987-8.

10 Peto J. Radon and the risks of cancer. Nature 1990;354:38990 .

11 Tomasek L, Darby SC, Swerdlow AJ, et al. Radon exposure and cancers other than lung cancer among uranium miners in West Bohemia. Lancet 1993;341:919-23.

12 Darby SC, Whitley E, Howe GR, et al. Radon and cancers other than lung cancer in underground miners: a collaborative analysis of 11 studies. F Natl Cancer Inst 1995; 87:378-84

13 Axelson O, Flodin U. Radon and leukaemia. Lancet 1989;ii: 99-100.

14 Forastiere F, Quercia A, Cavariani F, et al. Cancer risk and radon exposure. Lancet 1992;339:1115.

15 Sciocchetti G, Scacco F, Baldassini PG, et al. The Italian national survey of indoor radon exposure. Sci Total Environ 1985;45:327-33.

16 Orlando P, Lombardi S, Sciocchetti G, et al. Geological features and radon emitted from the soil in the Viterbo province. (In Italian.) Ambiente Risorse Salute 1990;104:19-22.

17 Sciocchetti G, Clemente FG, Ingrao G, et al. Results of a survey on radioactivity of building materials in Italy. Health Phys 1983;45:385-8.

18 Pershagen G, Gustav MD, Axelson O, et al. Residential radon exposure and lung cancer in Sweden. $N$ Engl f Med 1994;330:159-64.

19 Mele A, Szklo M, Visani G, et al. Hair dye and other risk factors for leukemia and pre-leukemia: a case control study. Am 7 Epidemiol 1994;139:609-19.

20 Bochicchio F, Campos Venuti G, et al. Results of the Bochicchio F, Campos Venuti G, et al. Results of the representative Italian nation
Health Phys 1996;71:741-8.

21 Lyman GH, Lyman CG, Johnson W. Association of leukemia with radium ground water contamination. $\mathcal{F} A M A$ 1985;254:621.

22 Fuortes L, McNutt LA, Lynch C. Leukemia incidence and radioactivity in drinking water in 59 Iowa towns. Am F Public Health 1990;80:1261.

23 Schottenfeld D, Fraumeni JF. Cancer epidemiology and prevention. Philadelphia: WB Saunders, 1982.

24 Draper GJ, ed. The geographical epidemiology of childhood leukaemia and non-Hodgkin lymphomas in Great Britain 1966-83. London, UK: Her Majesty's Stationary Office, 1991. (Studies on Medical and Population Subjects, No 53.)

25 Muirhed CR Childrod in the United States: a possible relation to population den-
sity? Cancer Causes Control 1995;6:383-8.

26 International Agency for Research on Cancer. IARC monograph on the evaluation of carcinogenic risks to humans. Vol 46. Diesel and gasoline engine exhausts and some nitroarenes. Lyon: IARC, 1989. 